\section{Fiebre y mialgias en mujer de 59 años}

\section{Sr. Director:}

Remitimos un caso que consideramos de interés por el diagnóstico diferencial que plantea propio de la Atención Primaria.

En plena época invernal con atención frecuente de casos de gripe en nuestra comunidad, se recibió en el centro de salud un aviso a domicilio de una mujer de 59 años que presentaba un cuadro de fiebre con mialgias y astenia de 3 días de evolución que le obligaba a guardar reposo en cama. No presentaba antecedentes personales de interés ni recibía tratamiento farmacológico. En la exploración habitual incluyendo auscultación cardiopulmonar e inspección de faringe, oídos, abdomen y extremidades no se apreció ninguna alteración. Las constantes eran normales a excepción de una temperatura de $38,7^{\circ} \mathrm{C}$. Se etiquetó de síndrome gripal y se pautaron analgésicos-antitérmicos (paracetamol) y rehidratación oral.

A los 5 días consultó nuevamente la familia por persistencia de la fiebre y gran astenia con debilidad muscular importante. Se acudió nuevamente al domicilio y se observó pérdida de fuerza de cinturas escapulares $(3 / 5)$ y cinturas pelvianas (3/5) con dolor a la palpación de musculatura proximal de extremidades superiores con pulso de arterias temporales normal. No refería alteraciones visuales ni mandibulares aunque refería cefalea no intensa. Se realizó estudio con radiografía de tórax y analítica sanguínea. La radiografía de tórax realizada en el día fue normal. La analítica que se recibió a los 3 días presentaba como signos destacados: $\mathrm{Hb}: 10,9 \mathrm{mg} / \mathrm{dl} \mathrm{y}$ VSG de $65 \mathrm{~mm} / 1 \mathrm{~h}$ con resto de parámetros normales (anemia normocítica normocrómica). Con dichos resultados se sospechó el diagnóstico de polimialgia reumática (PMR) y se realizó tratamiento empírico con corticoides por vía oral (prednisona a dosis de 20 $\mathrm{mg}$ /día) con mejoría espectacular del cuadro clínico desapareciendo la fiebre y el cuadro de debilidad muscular al cabo de una semana. Fue remitida para continuar estudio a consultas externas de medicina interna donde se realizó nueva determinación analítica con VSG de $15 \mathrm{~mm} / 1 \mathrm{~h}$ y biopsia de arteria temporal que resultó negativa. En la actualidad continúa asintomática con dosis mínimas de corticoides.

La PMR es una enfermedad de etiología desconocida que se asocia con frecuencia a arteritis de células gigantes (ACG), en torno a un 50\% de los casos de arteritis la presen$\tan ^{1}$, y aunque se han propuesto diversos criterios clínicos los más aceptados son edad su-perior a 50 años, VSG superior a $40 \mathrm{~mm} / 1 \mathrm{~h}$ y afectación severa proximal (de más de un mes y en al menos dos áreas entre cuello y cinturas escapular y pelviana) ${ }^{2}$. La respuesta a la terapia esteroidea también ha sido incluida por otros autores ${ }^{3}$. Como vemos, en sentido estricto, al no llevar un mes algunos autores no hubiesen realizado el diagnóstico, otros consideran suficiente 2 semanas ${ }^{4}$, pero 
dado el cuadro clínico y que cumplía el resto de criterios la buena respuesta al tratamiento esteroideo confirmó la sospecha. Una respuesta negativa a la semana excluye el diagnóstico. La dosis de corticoides necesaria en la PMR es inferior a la que se precisa en la $\mathrm{ACG}^{5}$ y en este caso dada la ausencia signos típicos de ACG como alteración visual se pautó la dosis inferior. En los casos de PMR que no presentan signos de ACG la mayoría de los autores indican que no se precisa realizar biopsia de la arteria temporal $^{6}$, pero sí es necesario un seguimiento ya que puede asociarse sobre todo los 2 primeros meses.

Queremos destacar con este caso que muchas enfermedades sistémicas, sobre todo reumatológicas, cursan con fiebre y que debemos pensar en ellas ante cuadros febriles sin foco de evolución prolongada para que no se nos pasen desapercibidas. No podemos contentarnos con realizar un diagnóstico de síndrome gripal o infección banal sin realizar una correcta exploración de los pacientes que quizás deberíamos haber efectuado de forma más concienzuda al inicio ya que la afectación muscular era evidente en la posterior exploración y nos orientó al diagnóstico. El médico de Atención Primaria está perfectamente capacitado para realizar el diagnóstico de esta enfermedad ya que sólo requiere criterios clínicos y una analítica rutinaria.

\section{R. Bartolomé Resano, F. J. Bar - tolomé Resano*, M. T. Bartolo - mé Resano**}

Médico de Familia. Centro de Salud de Berriozar. *Médico de Familia. Centro de Salud de II Ensanche. **DUE. Centro de Salud de II Ensanche. Pamplona. Navarra

\section{BIBLIOGRAFÍA}

1. Armona J, Rodríguez-Valverde V, González-Gay MA, Figueroa M, Fer-
nández-Sueiro JL, Blanco $\mathrm{R}$, et al. Arteritis de células gigantes. Estudio de 191 pacientes. Med Clin (Barc) 1995; 105: 734-7.

2. Chuang TY, Hunder GG, Ilstrup DM, Kurland LT. Polymyalgia rheumatica. A 10-year epidemiologic and clinical study. Ann Intern Med 1982; 97 : 672 80

3. Healey LA. Long-term follow-up of polymyalgia rheumatica: evidence for synovitis. Semin Arthritis Rheum 1984; 13: 322-8.

4. Bird HA, Esselinckx W, Dison ASJ, Mowat AG, Wood PHN. An evaluation of criteria for polymyalgia rheumatica. Ann Rheum Dis 1979; 38: 434-9.

5. Salvarani C, Macchioni P, Boiardi L. Polymyalgia rheumatica. The Lancet 1997; 350: 43-7.

6. Nolla JM, Valverde J, Dorca E, Carratalá J. La biopsia de la arteria temporal en la polimialgia reumática. Rev Esp Reumatol 1989; 16: 30-1.

\section{Hepatitis alcohólica en mujer con fiebre de origen desconocido}

\section{Sr. Director:}

Se debe sospechar una hepatitis alcohólica aguda en alcohólicos crónicos que en el curso de un periodo de intensificación de su ingesta presentan náuseas, vómitos, astenia, anorexia y al cabo de pocos días aparece una ictericia que adquiere un carácter colestásico con fiebre y dolor abdominal epigástrico. Se objetivan signos discretos de insuficiencia hepatocelular con transaminasas ligeramente elevadas, raramente sobrepasan las $300 \mathrm{U} / \mathrm{L}$, la aspartato aminotransferasa (GOT) es superior a la alanino aminotransferasa (GPT) con un cociente GOT/GPT mayor a 2. Suelen hallarse signos de colestasis, con hiperbilirrubinemia conjugada y elevación de fosfatasas alcalinas.

La mortalidad inmediata de la hepatitis alcohólica oscila entre el $10-25 \%$ de los casos y esta variabilidad viene determinada por la existencia de indicadores de mala evolución de la enfermedad como son una hiperbilirrubinemia supe- rior a $12 \mathrm{mg} / \mathrm{dl}$, una encefalopatía hepática, insuficiencia renal y tiempo de protrombina inferior al $50 \%$.

La hepatitis alcohólica es una lesión precirrótica y se ha considerado que sería el paso intermedio obligado para que los alcohólicos crónicos desarrollen una cirrosis hepática. En la esteatosis hepática la abstinencia de alcohol suele ser suficiente para conseguir la desaparición de las lesiones, aunque existen una serie de factores de predisposición individual que influyen en la progresión de la enfermedad, algunos pacientes de sexo femenino desarrollan una cirrosis a pesar de la abstinencia ${ }^{2}$.

Tienen, por tanto, las manifestaciones clínicas de la hepatitis alcohólica, personalidad propia que permiten orientar el diagnóstico antes de su confirmación histológica y dada la alta mortalidad inmediata es importante su sospecha diagnóstica ${ }^{2}$.

En este caso el diagnóstico no fue por sospecha sino dentro del estudio de una fiebre de origen desconocido y coincidió con el diagnóstico de seropositividad VIH (virus de inmunodeficiencia humana), lo que planteó la duda de si la fiebre estaba dentro del cuadro de primoinfección VIH o era secundaria a la hepatitis alcohólica aguda.

\section{CASO CLÍNICO}

Mujer de 32 años, fumadora de 1 paquete/día, bebedora de riesgo más de 7 UBE/día (unidad de bebida alcohólica), la primera vez que consulta por problemas relacionados con el alcohol es en 1999, se propone desintoxicación que no prosigue. Tres interrupciones voluntarias del embarazo, la última en febrero de este año, con controles ginecológicos posteriores correctos. Soltera, vive con sus padres con periodos largos de abandono del hogar con alguna pareja, volviendo con la ruptura de las mismas, en esos periodos se dedica a la venta ambulante. Niega adicción a drogas vía parenteral. 